\title{
Restoring the Architecture: A Rapid Clinical Perspective on Bone-Mineral Density and Osteoporosis
}

\author{
Linda Brand, De Wet Wolmarans* \\ Division of Pharmacology, Center of Excellence for Pharmaceutical Sciences, Faculty of Health Sciences, North West-University, \\ Potchefstroom, South Africa \\ *Corresponding author, email: dewet.wolmarans@nwu.ac.za
}

\begin{abstract}
Osteoporosis is a highly prevalent and debilitating condition that contributes to the risk of fracture in both women and men. The current paper will provide a rapid clinical overview of the condition and the current pharmacotherapeutic approaches applied in its treatment. We close with a summary of novel treatment strategies currently being developed and explain the role of sequential combination therapy in the management of established osteoporosis.
\end{abstract}

\section{A Concise Introduction to Skeletal Physiology}

The skeleton can be considered as the largest organ system in the human body, consisting of both an extensively mineralized matrix as well as a highly dynamic cellular compartment. Not only is the skeleton, in synergy with skeletal muscle, responsible for normal body posture and locomotion, it also functions as the primary calcium and phosphate store and hematopoietic organ. ${ }^{1,2}$ The skeletal architecture consists of two broad classes of bone, i.e. trabecular (spongy or cancellous) and cortical (dense) bone. Whereas cortical bone is mostly found in the shafts of long bones and makes up $80 \%$ of the skeletal mass, trabecular bone is the primary component of flat bone, e.g. the skull, ileum, and the scapula. However, trabecular bone is also located in the terminals of long bone, and lines its internal marrow-containing cavities. ${ }^{1}$ During adulthood, skeletal integrity is maintained by a constant process of remodeling that involves the coordinated resorption of existing bone and formation of new bone. This process is facilitated by the cellular fraction of bone and can result in significant pathology if the normal balance between resorption and adsorption is disrupted.

Apart from mineralized bone, the skeletal matrix also contains a number of collagen-derived and non-collagen-like proteins. These provide structural integrity and are important for the optimal mineralization and microstructural architecture of bone. ${ }^{3}$ Type 1 collagen is a rigid protein that is stabilized by the hydroxylation and cross-linking of its proline and lysine residues. ${ }^{1}$ As collagen on its own cannot provide the necessary integrity to bone, the matrix must be mineralized by calcium, phosphate, magnesium, and to a lesser extent sodium and potassium. This process is facilitated by osteoblast-derived alkaline phosphatase (ALP) that provides a trigger for initial crystallization. During the subsequent remodeling processes, collagen is cleaved and denaturized by collagenase, also secreted by osteoblasts.
Central to the bone remodeling process, two cell types, i.e. osteoblasts and osteoclasts, are locked in a constant power struggle. Indeed, the balance between optimal bone integrity and loss of bone-mineral density, can often, though not always, be related to the functional balance between bone-forming osteoblast and bone-degrading osteoclast action. Collectively, they elicit different physiological responses in a coordinated fashion, each performing an integral function in normal skeletal physiology. Further, their functions are regulated by several intercellular signaling molecules that form the framework underlying their collective efforts to maintain optimum bone integrity. As these physiological effects and regulatory mechanisms of osteoblast and osteoclast action are the focus of modern efforts to discover novel pharmacotherapeutic approaches to osteoporosis, they are summarized in Table 1.

\section{Regulators of bone remodeling}

Although bone remodeling occurs throughout life, different turnover rates are recorded at different stages of life. As such, during early adulthood, the rates of bone resorption and formation are equal, while during menopause resorption rates exceed formation capability. ${ }^{13}$ Apart from the intercellular mechanisms referred to in Table 1 - that mostly elicit their effects during the actual resorption and formation processes - bone remodeling is broadly regulated by a number of systemic and external factors, including physical exercise and changes in mechanical force, circadian rhythm and hormones. ${ }^{14} \mathrm{~A}$ number of these factors that are of interest in general practice will now be summarised:

- Parathyroid hormone (PTH): Acts via osteoblasts to induce osteoclast activity. Chronic and continuous excess induces osteoporosis, while intermittent administration, i.e. treatment with teriparatide (Forteo ${ }^{\circ}$ ), stimulate bone formation. ${ }^{15}$ 


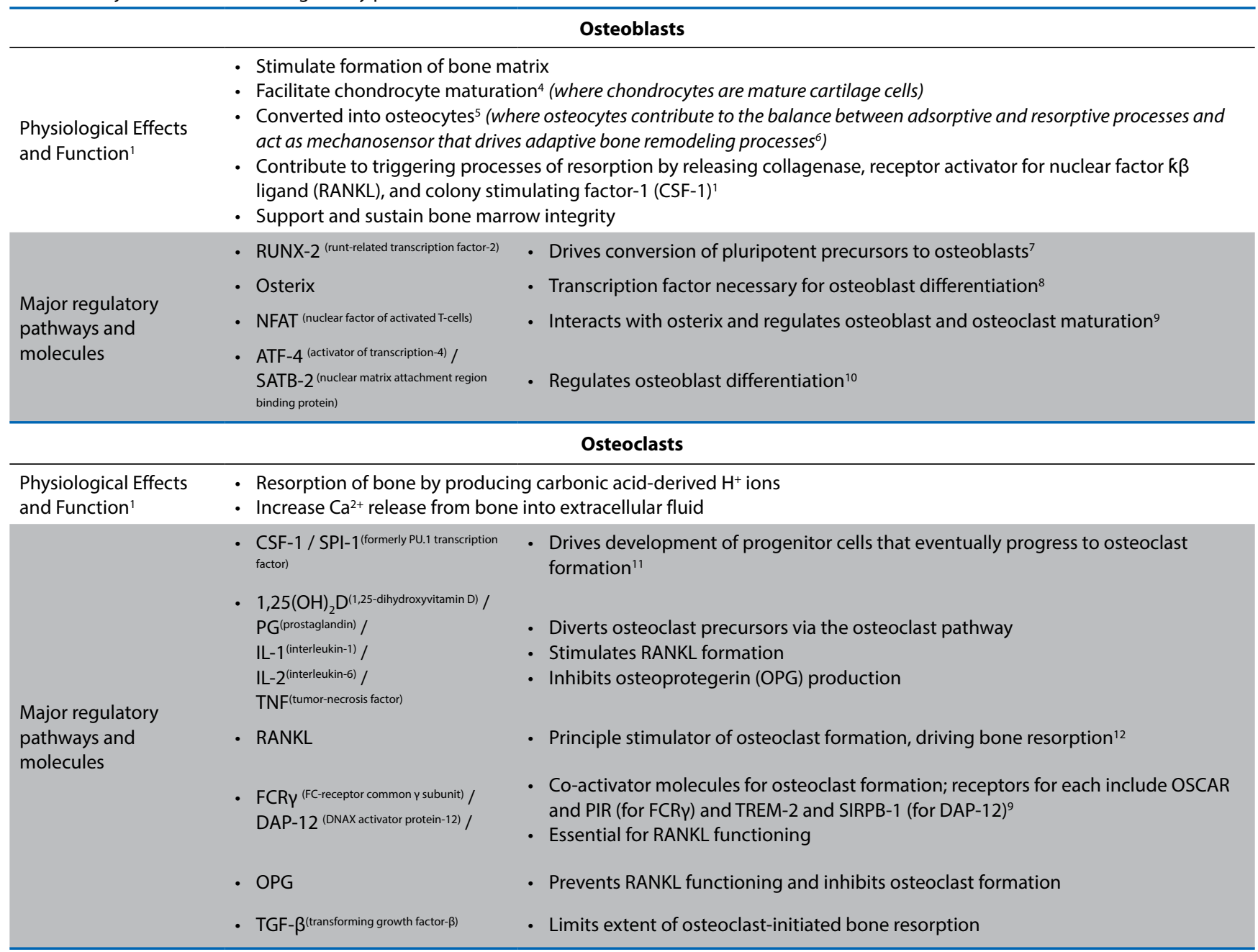

- Vitamin D: Vital for calcium and phosphate absorption. Speculated to exert direct effects on bone, but the relevance of such actions has not yet been established. High concentrations induce RANKL expression on osteoblasts, reducing collagen formation.

- Calcitonin: Known to inhibit osteoclastic action and reduce bone turnover. However, no significant pathological manifestations are observed in conditions of chronic calcitonin excess or deficiency, while its mechanism of action in bone remodeling remains unclear. ${ }^{16}$

- Growth hormone: Most important driver of bone formation during childhood. Increases synthesis and release of insulinlike growth factor-1 (IGF-1), stimulating osteoblastic action and cartilage growth. ${ }^{17}$

- Corticosteroids: Being one of the drug classes most often prescribed in clinical practice, glucocorticoids exert important effects across all aspects of bone remodeling. Glucocorticoids reduce intestinal calcium absorption, increase RANKL and CSF-1 production, ${ }^{18}$ decrease IGF-1 production, and diminish the osteoblastic cell population. ${ }^{19}$

- Thyroid hormone: Important for cartilage formation, especially during childhood. Also bolsters bone resorption and collagenase production during adulthood. ${ }^{20}$
- Insulin: Facilitates bone formation. Hyperinsulinemia during pregnancy results in increased fetal bone mass, while uncontrolled diabetes, especially type-1, impairs skeletal growth during childhood. ${ }^{21}$

- Sex steroids: Play a known, although unclear, role in bone formation. Estrogen is responsible for epiphyseal closure at the end of puberty, while estrogen and testosterone deficiency is associated with reductions in bone-mineral density, possibly due to increased sensitivity to IL-1, IL-6, and TNF- $a^{22}$

\section{Clinical evaluation and interpretation of bone-mineral density}

While a comprehensive overview of the clinical evaluation of bone-mineral density falls outside the scope of the current review, a basic understanding of interpreting bone densitometry results is valuable. Essentially, bone-mineral density results are viewed considering the young adult norm (T-scores) or the agespecific mean of a given population (Z-scores). With the aid of software (FRAX), T- and Z-scores are subsequently combined with other risk indicators, e.g. familial history, race, body composition and activity level, to deliver a more accurate clinical picture and prognostic status. ${ }^{23}$ Generally, the more negative the $\mathrm{T}$ - and Z-score, the worse the clinical prognosis will be, and vice versa. Changes in T-and Z-scores will furthermore often be noted in trabecular, rather than cortical bone. This is due to the fact 
that the surface area available for bone remodeling processes in trabecular bone is much larger compared to that of cortical bone. ${ }^{1}$

To date, very few advances have been made in elucidating biochemical markers of metabolic bone disease, e.g. osteoporosis. However, one such marker, i.e. ALP, has at least some demonstrable usefulness. Although not overly useful in the diagnosis of osteoporosis, determinations of ALP are used to assess clinical status in Paget's disease, rickets, and hyperparathyroidism (where ALP concentrations and disease progression rates are positively correlated). That being said, high levels of ALP also demonstrate a positive correlation with fracture incidence in post-menopausal women and may be considered as a valuable marker of fracture risk. ${ }^{24}$

For a detailed review of other diagnostic markers of boneturnover of relevance in the South African context, the reader is referred to The South African Clinical Guideline for the Diagnosis and Management of Osteoporosis (2017) released by the National Osteoporosis Foundation of South Africa. ${ }^{25}$

\section{Osteoporosis: A fundamental consequence of reduced bone-mineral density}

Being the most common metabolic bone disease, osteoporosis will result in at least one fracture in half of white and Asian women and one in eight men and women of other racial backgrounds. ${ }^{1}$ The condition can be defined as 'a disease being characterized by low bone mass and microarchitectural deterioration.'26 Briefly, although somewhat arbitrary, primary osteoporosis refers to a 'normal' age-related decline in bone-mineral density, whereas secondary osteoporosis implicates a different etiological trigger. Broadly, osteoporosis can be triggered by either failure to reach peak bone mass or excessive bone loss. ${ }^{27}$ In turn, these can be influenced by many intrinsic and extrinsic factors, summarized in Table 2.

The most common clinical manifestation of osteoporosis is fractures. ${ }^{32}$ Compression fractures of the vertebrae, often noted in the thoracic vertebrae below T6, are the most prevalent. While many patients present with a fracture in only one vertebra, others may demonstrate the involvement of multiple vertebrae. ${ }^{32}$ The clinical consequences of severe vertebral deformities are significant and can often include back pain, reductions in vital capacity, and rib impingement. ${ }^{33}$ Hip fracture of the proximal femur remains a challenge in older adults at higher risk of falling. Treatment mainly involves expensive surgery associated with a relatively high mortality rate of up to $20 \%$. Further, most elderly patients heal slowly from physical trauma and post-operative surgery and will as such often not reach the level of physical health akin to that before suffering from a hip fracture. ${ }^{34}$ Other fractures that occur in osteoporotic patients include Colles' fractures of the distal radius and bisphosphonate-associated atypical femoral fractures.

Table 2: Factors contributing to the development of primary and secondary osteoporosis

\begin{tabular}{|c|c|}
\hline \multicolumn{2}{|r|}{ Primary Osteoporosis } \\
\hline Inadequate peak bone mass & $\begin{array}{l}\text { - Primarily influenced by genetic predisposition }{ }^{28} \\
\text { - Childhood and pubertal factors that may contribute to lower peak bone mass include inadequate nutrition, } \\
\text { sedentary lifestyle, comorbid illness, e.g. seizures, hyperthyroidism, type-1 diabetes mellitus, etc. } \\
\text { Of important consideration in South Africa is the widespread and chronic use of progesterone-alone } \\
\text { contraceptives, i.e. depo-medroxyprogesterone acetate (Depo-Provera"). The widespread advocacy for its use } \\
\text { in pubertal women may contribute to such individuals not reaching optimum peak bone mass. Indeed, it has } \\
\text { been demonstrated that hip and spine bone-mineral density reduce with } 0.5 \%-3.5 \% \text { after one year of use, and } \\
\text { with } 5.7 \%-7.5 \% \text { after two years of use. Although the clinical relevance of such reductions has not yet been } \\
\text { established in full, it is advised that this possibility be considered during diagnostic evaluations. }{ }^{29} \\
\text { - Reduced calcium and vitamin D intake }\end{array}$ \\
\hline Excessive bone loss & $\begin{array}{l}\text { - Loss of estrogen's protective effects in both men and aging women }{ }^{30} \\
\text { - Hormonal abnormalities, i.e. excessive parathyroid hormone }\end{array}$ \\
\hline
\end{tabular}

\section{Secondary Osteoporosis}

\begin{tabular}{|c|c|}
\hline Nutrition and lifestyle ${ }^{1}$ & $\begin{array}{l}\text { - Low protein intake } \\
\text { - Vitamin K deficiency } \\
\text { - High lean body mass (presumably due to lower adipose conversion of androgen to estrogen) } \\
\text { - Smoking } \\
\text { - Loss of muscle strength }\end{array}$ \\
\hline Comorbid pathologies ${ }^{31}$ & $\begin{array}{l}\text { - Chronic obstructive airway disease and asthma } \\
\text { - Cystic fibrosis } \\
\text { - Gastrointestinal disease, e.g. inflammatory bowel disease } \\
\text { - Endocrine disorders, e.g. thyrotoxicosis, Cushing's syndrome, and acromegaly } \\
\text { - Connective tissue disorders, e.g. homocystinuria and osteogenesis imperfecta } \\
\text { - Neoplasm } \\
\text { - Haematopoietic disorders, e.g. systemic mastocytosis, plasma cell dyscrasia } \\
\text { - Ankylosing spondylitis }\end{array}$ \\
\hline Drug and substance use ${ }^{1}$ & $\begin{array}{l}\text { - Chronic high-dose glucocorticoids } \\
\text { - Anti-epileptics } \\
\text { - Immunosuppressive drugs (other than glucocorticoids) } \\
\text { - Excessive alcohol consumption } \\
\text { - Heparin }\end{array}$ \\
\hline
\end{tabular}




\section{Current pharmacotherapeutic approaches to osteoporosis}

Primary goals of treatment can be divided into the following categories: ${ }^{25}$

- Preventing osteoporosis, by optimizing bone density during childhood and adolescence, thereby reducing the future incidence of fractures;

- Stabilization or improvement of bone mass and strength and prevention of fractures when osteopenia or osteoporosis is already present; and

- Pain management and reduction of deformities, improvement of functional capacity to prevent further fracturing as well as the promotion of general well-being in patients with established osteoporotic fractures.
While optimal prevention and management of osteoporosis will ultimately include both lifestyle intervention, inter alia physical exercise and appropriate dietary adjustment, the present review will focus on the pharmacotherapeutic options that are currently available in South Africa. As such, bone-active drugs are broadly classified into anti-resorptive agents (aid in the prevention of bone loss and the improvement of bone strength), osteoanabolic drugs (stimulation of bone formation), and agents with a dual action on bone (strontium) (Table 3). While a few novel agents used in the management of osteoporosis elsewhere are not yet registered in South Africa, they may be entered into the local market eventually and will be highlighted later; however, they are not included in Table 3.

Table 3: Currently available pharmacotherapeutic agents for the prevention and treatment of osteoporosis in South Africa

\begin{tabular}{|c|c|c|c|}
\hline Active ingredient & $\begin{array}{l}\text { Examples of trade } \\
\text { names }\end{array}$ & Strength, preparation, and dosage & General comment \\
\hline \multicolumn{4}{|c|}{ BISPHOSPHONATES } \\
\hline $\begin{array}{l}\text { Alendronate sodium / } \\
\text { alendronic Acid }\end{array}$ & $\begin{array}{l}\text { Fosamax daily / Femax / } \\
\text { Fosagen } \\
\text { Fosamax weekly / } \\
\text { Osteobon / Osteonate / } \\
\text { Sandoz Alendronate }\end{array}$ & 10 mg tablets; 1 daily & \multirow{3}{*}{$\begin{array}{l}\text { - Check before treating that patient's serum } \\
\text { - Caution in renal impairment } \\
\text { - To improve absorption, tablets should } \\
\text { be taken on an empty stomach, sitting } \\
\text { upright, } 30 \text { minutes before any other food } \\
\text { or drink }\end{array}$} \\
\hline $\begin{array}{l}\text { Alendronate sodium + } \\
\text { cholecalciferol }\end{array}$ & Fosavance & $\begin{array}{l}70 \mathrm{mg}+70 \mu \mathrm{g}(2800 \mathrm{IU}) \text { tablets; } \\
1 \text { weekly }\end{array}$ & \\
\hline $\begin{array}{l}\text { Risedronate sodium / } \\
\text { risedronic acid }\end{array}$ & Actonel / Actamax & 35 mg tablets; 1 weekly & \\
\hline \multirow[b]{2}{*}{$\begin{array}{l}\text { Ibandronate sodium / } \\
\text { ibandronic acid }\end{array}$} & Boniva & $\begin{array}{l}150 \text { mg tablet monthly; or } 3 \text { mg IVI } \\
\text { every } 3 \text { months }\end{array}$ & \multirow{4}{*}{$\begin{array}{l}\text { - Acute phase response } \\
\text { - Musculoskeletal symptoms }\end{array}$} \\
\hline & Bondronat & $\begin{array}{l}2 \mathrm{mg} / 2 \mathrm{ml} \text { and } 6 \mathrm{mg} / 6 \mathrm{ml} \mathrm{IVl} \text {; } \\
\text { every } 3-4 \text { weeks in bone metastatic } \\
\text { malignancy }\end{array}$ & \\
\hline \multirow[t]{2}{*}{ Zoledronic acid } & $\begin{array}{l}\text { Zomabon / Zomedron / } \\
\text { Zometa }\end{array}$ & $\begin{array}{l}4 \text { mg IVl; every } 2-4 \text { weeks in bone } \\
\text { metastatic malignancy }\end{array}$ & \\
\hline & Aclasta & 5 mg IVl; every year & \\
\hline \multicolumn{4}{|c|}{ CALCIUM } \\
\hline $\begin{array}{l}\text { Calcium carbonate / calcium } \\
\text { citrate / calcium lactate / } \\
\text { calcium phosphate / calcium } \\
\text { gluconate }\end{array}$ & $\begin{array}{l}\text { Caltrate / Menacal / } \\
\text { B-Cal-D }\end{array}$ & $\begin{array}{l}\text { Recommended daily intake: } \\
\text { - Men: } 1.3-1.5 \mathrm{~g} \\
\text { - Women: } 0.8-1.0 \mathrm{~g}\end{array}$ & $\begin{array}{l}\text { - Calcium carbonate is low-priced but is } \\
\text { poorly tolerated by some, with complaints } \\
\text { of constipation, bloating abdominal cramps } \\
\text { - Calcium carbonate, but not calcium } \\
\text { citrate, should be taken with meals }\end{array}$ \\
\hline \multicolumn{4}{|c|}{ VITAMIN D } \\
\hline $\begin{array}{l}\text { Vitamin } D_{2} \text { (ergocalciferol) / } \\
\text { Vitamin } D_{3} \text { (cholecalciferol) }\end{array}$ & & $\begin{array}{l}\text { Recommended daily intake: } \\
400-1000 \text { IU daily }\end{array}$ & $\begin{array}{l}\text { Fundamental for optimal calcium } \\
\text { absorption and countering compromised } \\
\text { calcium transport in osteoporosis }\end{array}$ \\
\hline $\begin{array}{l}\text { 1,25-dihydroxyvitamin } \mathrm{D}_{3} \\
\text { (calcitriol) }\end{array}$ & $\begin{array}{l}\text { Rocaltrol / A-Lennon } \\
\text { Calcitriol }\end{array}$ & $\begin{array}{l}0.25 \mu \mathrm{g} \text { tablets; weekly, daily or twice } \\
\text { daily }\end{array}$ & $\begin{array}{l}\text { Dosage and response dependent on } \\
\text { serum calcium concentrations } \\
\text { - Dose monitoring needed }\end{array}$ \\
\hline Calcidiol (1-hydroxyvitamin $\mathrm{D}_{3}$ ) & One-Alpha & $0.25 \mu \mathrm{g}$ and $1 \mu \mathrm{g}$ tablets; $1 \mu \mathrm{g}$ daily & $\begin{array}{l}\text { - Used primarily in patients diagnosed with } \\
\text { kidney failure and renal osteodystrophy }\end{array}$ \\
\hline \multicolumn{4}{|c|}{ SEX HORMONES AND SEX HORMONE MODULATORS } \\
\hline Raloxifene & Evista & 60 mg tablets; 1 daily & $\begin{array}{l}\text { - Reduces risk for estrogen-sensitive breast } \\
\text { cancer / no clinical effect on endometrium } \\
\text { - Significant risk of venous } \\
\text { thromboembolism } \\
\text { - Exacerbation of menopausal symptoms }\end{array}$ \\
\hline Tibolone & Livifem & 2.5 mg tablets; 1 daily & $\begin{array}{l}\text { - Initiate only } 12 \text { months after last } \\
\text { menstrual period as it may cause irregular } \\
\text { vaginal bleeding } \\
\text { - Improves climacteric symptoms } \\
\text { - Decreases risk of colon and breast cancer } \\
\text { - Increased stroke risk in patients }>60 \text { years }\end{array}$ \\
\hline
\end{tabular}




\begin{tabular}{|c|c|c|c|}
\hline \multirow{2}{*}{ Estrogen derivatives } & $\begin{array}{l}\text { Premarin / Estrofem / } \\
\text { Estradot / Evorel }\end{array}$ & Various strengths & $\begin{array}{l}\text { - Consider in perimenopause or early } \\
\text { menopause } \\
\text { - Use only in women who underwent a } \\
\text { complete hysterectomy } \\
\text { - Venous thromboembolism risk } \\
\text { - Increased risk of breast cancer, } \\
\text { cardiovascular disease, and stroke }\end{array}$ \\
\hline & $\begin{array}{l}\text { Premelle Cycle / } \\
\text { Angelique / Activelle }\end{array}$ & Various strengths and combinations & $\begin{array}{l}\text { - Consider in perimenopause or early } \\
\text { menopause } \\
\text { - Use in women with no or only a partial } \\
\text { hysterectomy } \\
\text { - Venous thromboembolism risk } \\
\text { - Increased risk of breast cancer, } \\
\text { cardiovascular disease, and stroke }\end{array}$ \\
\hline \multicolumn{4}{|c|}{ PARATHYROID HORMONE ANALOGUES } \\
\hline Teriparatide & Forteo & $\begin{array}{l}250 \mu \mathrm{g} / \mathrm{ml} \mathrm{SCl}(20 \mu \mathrm{g} / \text { dose in } 3 \mathrm{ml} \\
\text { pre-filled pen) }\end{array}$ & $\begin{array}{l}\text { - Daily } \mathrm{SCl} \text { in thigh or abdomen } \\
\text { - Duration of treatment should not exceed } \\
18 \text { months }\end{array}$ \\
\hline \multicolumn{4}{|c|}{ STRONTIUM } \\
\hline Strontium ranelate & Protos & $2 \mathrm{~g} /$ sachet; daily in a glass of water & $\begin{array}{l}\text { - Administered on an empty stomach } \\
\text { - Increased risk of myocardial infarction } \\
\text { and deep vein thrombosis }\end{array}$ \\
\hline
\end{tabular}

\section{The bisphosphonates}

Bisphosphonates are the mainstay of anti-resorptive therapy and are the most frequently used drugs for the prevention and treatment of osteoporosis. For a list of bisphosphonates currently registered in South Africa, refer to Table 3. Bisphosphonates, being carbon-substituted analogs of pyrophosphate, bind to hydroxyapatite (a complex phosphate of calcium that occurs as a mineral and is the chief structural element of vertebrate bone), are absorbed by bone and concentrate at sites of active bone remodeling. As such, they are incorporated in the bone matrix where they lie dormant, being activated only during osteoclastic acidification and thereby preventing resorption. ${ }^{35}$ Once incorporated in the skeleton, they are released only during processes of bone turnover. There are two subclasses of bisphosphonates, one group without a nitrogen $(\mathrm{N})$ in the side chain, and the $\mathrm{N}$-containing (or amino-) bisphosphonates. Interestingly, the amino-bisphosphonates also inhibit multiple steps in the biosynthesis of cholesterol from mevalonate (HMGCoA reductase pathway), proposed to be critical for osteoclast function and survival. ${ }^{36}$ This may partially explain at least some of the clinical differences between the effects of different bisphosphonates and may also account for the potential positive effects observed in some studies of the statins on bone mineral homeostasis. However, the clinical efficacy of the statins, indicated for dyslipidemias, in osteoporosis is controversial. ${ }^{37}$

Bisphosphonates can be administered orally and as intravenous solutions (Table 3). The bioavailability of oral bisphosphonates is limited and absorption is $<5 \%$ with a further reduction in the absorbed fraction in the presence of food. ${ }^{38}$ As bisphosphonates can elicit severe gastric erosion if they are in contact with the gastric mucosa for prolonged durations, they should be taken on an empty stomach only with a full glass of water, while food, other medication or drinks should be avoided for at least half an hour after taking the tablet. Further, to accelerate its absorption, patients should remain upright for at least 1-2 hours after oral administration. ${ }^{38}$ While the use of weekly, as opposed to daily formulas significantly reduces the risk of said adverse reactions, the same instructions apply. Intravenous administration not only increases the bioavailability but also reduces the need for frequent administration, e.g. zoledronic acid that can be infused annually. While the bisphosphonates are contraindicated for use in renal insufficiency with a creatinine clearance of $<30 \mathrm{ml} / \mathrm{min}$, appropriate dose adjustments have not been determined. ${ }^{36}$

As alluded to earlier, oral bisphosphonates may cause significant esophageal and gastric irritation, heartburn, esophagitis, abdominal pain, distension, constipation or diarrhea. Still, gastrointestinal adverse effects may even occur following IV administration. ${ }^{39}$ Other adverse effects include headache, musculoskeletal pain (may be severe), nausea and vomiting, rash, pruritus and in rare instances, severe skin reactions, i.e. Stevens-Johnson syndrome and toxic epidermal necrolysis. ${ }^{39}$ Intravenous zoledronic acid has been reported to cause headache, anemia, conjunctivitis, skeletal pain, myalgia and arthralgia, renal impairment with increased serum creatinine and urea concentrations, as well as hypophosphatemia and hypocalcemia. ${ }^{39}$

An important and serious complication, having prompted the American Food and Drug Administration (FDA) to issue an alert on the labeling of the bisphosphonates in 2004, is osteonecrosis of the jaw (ONJ). ${ }^{40}$ An increased risk for bisphosphonate-induced ONJ may occur when a patient has a history of dental conditions, i.e. invasive dental procedures, periodontal disease and dental trauma. ${ }^{41}$ However, the incidence is relatively low (1/10 000 patients per year for IV bisphosphonates and 1/100 000 patients per year for the oral bisphosphonates). Still, in extensive bibliographical analyses of papers published between 2003 and 2014 , it was found that ONJ develops in $0.001-1.01 \%$ of patients using bisphosphonate therapy, a significantly higher incidence compared to the general population $(<0.001 \%)$; the highest incidence was noted in patients with cancer (1-15\%).42,43 Although it is clear that ONJ is a time and dose-related side 
effect, the time to onset of bisphosphonate-associated ONJ was found to be 6 and 2 years for oral alendronate and intravenous zoledronate, respectively. Stratified by condition, the time of onset was 5 and 2 years for patients with osteoporosis and cancer respectively. ${ }^{44}$ Importantly, no evidence has been presented that drug-free intervals are of any benefit in the management of ONJ. ${ }^{42}$

More recently, concern over the benefit vs. risk ratio of long-term bisphosphonate use led the FDA to issue a warning relating to an increased risk of atypical sub-trochanteric fractures of the femur (AFFs) that may occur spontaneously and present with or without prodromal pain or any apparent trauma. ${ }^{45}$ As bisphosphonates cause prolonged suppression of bone remodeling, they may contribute in deteriorating the skeletal microarchitecture. ${ }^{46}$ Therefore, it is recommended that individuals be routinely evaluated for the appropriateness of continued therapy during the long-term use of bisphosphonates. Interestingly, as opposed to guidelines for the management of $\mathrm{ONJ}$, drug-free intervals are one of the recommendations made with respect to AFFs in a new position statement of the European Menopause and Andropause Society (EMAS). It is advocated that alendronate is discontinued for a period of 5 years and risedronate for 1-2 years in patients treated for more than 5 years with either drug. With respect to zolendronate, the recommendation is a drug-free interval of 6 years following 3 years of treatment. ${ }^{47}$ The choice to terminate bisphosphonate therapy is, however, still controversial. However, patients with a low risk of fractures (younger patients without a fracture history and with a bone mineral density approaching normal) seem unlikely to benefit from treatment beyond this period. Importantly, once an atypical fracture does occur, bisphosphonates should be withdrawn, and calcium and vitamin D supplemented. ${ }^{46}$ For detailed recommendations relating to fracture risk assessment and management, the reader is referred to The South African Clinical Guideline for the Diagnosis and Management of Osteoporosis (2017)..$^{25}$

\section{Calcium and vitamin D}

Adequate calcium intake (preferably from dietary sources) is essential in the prevention of secondary hyperparathyroidism and bone destruction and for the maintenance of general bone health. ${ }^{48}$ Adequate intake values vary throughout life and if such dietary intake is inadequate, supplementation is suggested. An amount of 700-1200 mg/day is generally recommended for the prevention and treatment of postmenopausal osteoporosis. ${ }^{48}$ Although calcium increases bone-mineral density, there is, however, no consistent proof that higher than recommended levels reduce fracture risks. ${ }^{48}$ It should be combined with vitamin $\mathrm{D}$ and osteoporosis drugs when necessary. Concerns have been raised about possible harmful effects, including an increased risk for cardiovascular events, urolithiasis and even fractures resulting from excessive calcium intake (> $2000 \mathrm{mg} /$ day). Some studies even suggest the possibility of harmful effects at lower intake, but this issue remains unresolved. ${ }^{48-52}$

Calcium supplements are available in many salt formulations, the most popular being calcium carbonate or calcium citrate.
Formulations typically contain 250 to $600 \mathrm{mg}$ of elemental calcium per tablet. Importantly, the fraction of calcium absorbed demonstrates an inverse relationship with the dose administered and, as such, a maximum single dose of $\leq 600 \mathrm{mg}$ is recommended. ${ }^{48}$ In this regard, a suggestion made in the most recent clinical guide of EMAS may be noteworthy: "Women who do not wish to take supplements and who have problems in maintaining a diet sufficiently rich in calcium should be reassured that this is unlikely to affect adversely their fracture risk. Other measures, like physical activity and vitamin D supplements, may help to maintain bone health." ${ }^{47}$

Vitamin $D$ refers to two related fat-soluble substances, cholecalciferol (vitamin $D_{3}$ ) and ergocalciferol (vitamin $D_{2}$ ) that share the capacity to prevent or cure rickets. ${ }^{53}$ Vitamin D exerts an active role in calcium homeostasis and is regarded as a hormone, rather than a vitamin..$^{53}$ Vitamin $D$ is synthesized in the skin after exposure to sunlight, hydroxylated in the liver and converted from the inactive 25-hydroxyvitamin $D$ (measured in serum for diagnosis), to the active form, viz. 1,25-dihydroxyvitamin D (calcitriol) in the kidneys. ${ }^{54}$ The recommended intensity of sun exposure to achieve adequate vitamin $D$ levels is 5 to 15 minutes (longer for patients with darker skin) of direct sunlight (depending on the time of year and latitude) four to six times a week. ${ }^{54}$ Supplemental vitamin D maximises intestinal calcium absorption, indirectly promoting bone mineralization and reduce fractures. ${ }^{53}$ There is no consensus regarding optimal vitamin D intake. ${ }^{53}$ Oral supplementation with 400-1 $000 \mathrm{IU}$ of cholecalciferol daily (maintenance dose) is usually adequate to treat insufficiency. Higher doses prescription ergocalciferol (vitamin D2) or calcitriol regimens weekly, monthly or quarterly, may be used for replacement and maintenance therapy.

\section{Sex hormones and sex hormone regulators}

\section{Estrogen derivatives}

Estrogen is crucial for maintaining a normal balance between osteoblasts and osteoclasts, and hormone deficiency following menopause is a significant risk factor for the development of osteoporosis in women. ${ }^{55}$

Estrogen's anti-resorptive mechanism involves the reduction of osteoclast-stimulating cytokines in the serum and increasing TGF- $\beta$ (see Table 1). ${ }^{56,57}$ While menopausal hormone replacement therapy (HRT; estrogen with or without progesterone) has long been known to increase bone-mineral density and reduce fracture risk, ${ }^{53,58}$ recent findings confirmed said benefits. ${ }^{59}$ That said, HRT is associated with some risk, including cardiovascular disease, thromboembolic disease, stroke and breast cancer. ${ }^{53,59-61}$ These agents have therefore largely been abandoned as first-line treatment for osteoporosis and are currently recommended for the short-term management of vasomotor symptoms such as hot flushes associated with menopause in women who are not at an increased risk for cardiovascular disease..$^{53} \mathrm{It}$ is also recommended that the lowest effective dose for the prevention and treatment of menopausal symptoms should be used and discontinued as soon as possible. Annual individualized risk-benefit assessments should be done..$^{53}$ Contrary to these recommendations, some 
experts believe, based on a further review of the available data, that estrogen may be a valuable option for patients younger than 60 years, ${ }^{62}$ providing that therapy is individualized for each patient. This is, however, an ongoing debate. ${ }^{63-65}$ Independent of oral or transdermal formulations and whether it is administered in a continuous or cyclic regimen, similar dose-dependent effects on bone-mineral density have been found at equivalent doses. ${ }^{1}$

\section{Raloxifene}

Raloxifene is a selective estrogen receptor modulator (SERM); it acts as an estrogen agonist on bone and liver tissue, has no demonstrable activity in the uterus and is an antagonist on estrogen receptors in breast tissue. ${ }^{53}$ Raloxifene is indicated for the prevention and treatment of postmenopausal osteoporosis, as it stabilizes and modestly increases bone mineral density and reduces vertebral fracture risk. ${ }^{53,66}$ Although the currently available SERMs do have a favorable selectivity towards bone tissue, they are however not as effective in skeletal tissue if compared to classical HRT preparations. ${ }^{57}$

\section{Tibolone}

Tibolone is a synthetic steroidal agonist with estrogenic, progestogenic and weak androgenic actions. ${ }^{67}$ With the exception of the USA, it is used worldwide, ${ }^{68}$ mainly for the treatment of endometriosis, as well as for HRT in post-menopausal women and the prevention of postmenopausal osteoporosis. ${ }^{69}$ While tibolone has similar efficacy compared to conventional hormone replacement formulas, it also shares a similar side effect profile. ${ }^{67}$ Tibolone exerts no estrogenic action in endometrial and breast tissue but has estrogenic effects in bone tissue, the vagina, and the brain (neuroprotective effects). ${ }^{70}$ The compound also presents with significant progestogenic effects in the breast and endometrium. Its androgenic activity is mainly focused on the brain and liver. ${ }^{70}$ Beneficial effects other than on bone-mineral density are that tibolone was shown to reduce the risk of breast and colon cancers. ${ }^{71}$ Moreover, use of the compound results in fewer hot flushes and symptoms of vaginal dryness, while its progestogenic action protects from endometrial thickening. Androgenic benefits include improvement in mood and libido. ${ }^{71}$ By alleviating climacteric symptoms, tibolone may be an alternative for women in the early postmenopausal stage. ${ }^{69,71}$

Tibolone is generally well-tolerated and the most common side effects reported are weight gain, bloating and edema. ${ }^{72}$ Nausea, headache, acne, facial hirsutism, breast tenderness and vaginal bleeding have also been reported. ${ }^{73}$ The question of whether tibolone may be cardioprotective as was previously suggested ${ }^{74}$ still remains unanswered. For patients who have recently been switched from another HRT regimen, it is recommended that progesterone should be added for 10 days every 3 months to minimise irregular bleedings..$^{67,72}$

\section{Teriparatide}

Teriparatide, a recombinant form of human parathyroid hormone, is the only skeletal anabolic therapy currently available in South Africa. Continuous hyperparathyroidism may cause bone demineralization and osteopenia; however, intermittent
PTH administration stimulates osteoclast-induced osteoblast activity. ${ }^{53}$ It has been demonstrated to significantly increase bone-mineral density in the lumbar spine and hip, and reduce the risk of vertebral and non-vertebral fractures. ${ }^{53,75-77}$ That said, long-term pre-clinical toxicology studies demonstrated an increased prevalence of osteosarcoma, ${ }^{78}$ mandating a black-box warning by the FDA. Given the fact that the safety and efficacy of teriparatide have not been evaluated for continuous use exceeding 2 years, it is recommended that the maximum duration of treatment should not exceed 18 months to 2 years. ${ }^{53,54,79}$ The use of teriparatide is contra-indicated in patients who are at an increased baseline risk for osteosarcoma, i.e. individuals with Paget's disease, unexplained alkaline phosphatase elevations, growing individuals, or patients where prior radiation therapy involved the skeleton..$^{53}$ Teriparatide is otherwise well-tolerated with reports of nausea, headache and leg cramps. ${ }^{76}$ Following discontinuation of teriparatide, bone-mineral density status deteriorates rapidly; consolidation therapy with an antiresorptive drug after the 18-month treatment course is not only recommended ${ }^{54}$ but essential to prevent post-teriparatide bone loss. ${ }^{80}$ Importantly, the beneficial effects of teriparatide on bone formation may be undermined by previous long-term use of bisphosphonates, ${ }^{54}$ although results of the combination of teriparatide and antiresorptive agents, especially the bisphosphonates are inconclusive. ${ }^{81}$

Teriparatide is indicated for postmenopausal osteoporosis, osteoporosis in men and corticosteroid-induced osteoporosis in patients with a $T$-score of $\leq-2,5$ plus $\geq 2$ fragility fractures, or in those who have failed on, or are intolerant of previous bisphosphonate therapy. ${ }^{79}$

\section{Strontium}

Strontium is an alkaline earth metal with similar physical and chemical properties as calcium, enabling strontium to be incorporated into the mineral phase of bone. Strontium ranelate has a dual action on bone, promoting bone formation, i.e. increasing pre-osteoblast proliferation, osteoblast differentiation, type 1 collagen synthesis and bone matrix mineralization, as well as reducing osteoclast-induced resorption..$^{82}$ Indeed, strontium ranelate significantly improves bone mass and quality and increases bone strength through changes in bone matrix properties and bone-mineral density. It also reduces the risk of vertebral and non-vertebral fractures..$^{83-85}$

Results of a large comparative study based on the available data from primary publications and regulatory documents relating to its adverse effects, however, indicated that the risks of strontium ranelate are of equal importance as its benefits, ${ }^{86}$ i.e. increasing the risk of myocardial infarction, as well as of pulmonary and venous thromboembolism. ${ }^{86}$ That said, excluding patients with existing cardiovascular contraindications from the analysis of randomised clinical trials appears to negate the increased $\mathrm{MI}$ risk. Strontium, therefore, remains a viable option when other osteoporosis treatments are contraindicated. ${ }^{87}$ 


\section{Agents not registered in South Africa and novel approaches to the treatment of osteoporosis}

Denosumab, a potent antiresorptive drug, has been authorized since 2010 by both the European Commission and the United States FDA for the treatment of inter alia postmenopausal women with osteoporosis with a high risk of fracture. ${ }^{88}$ Denosumab is a human monoclonal antibody that prevents bone resorption by inhibiting the actions of RANKL (see Table 1). ${ }^{54}$ Its antiresorptive action differs from the bisphosphonates in that the bisphosphonates inhibit osteoclast function and survival, but have no effect on osteoclast formation. ${ }^{89}$ It has been shown to increase bone-mineral density and reduce vertebral as well as nonvertebral fractures (including hip fractures). ${ }^{89}$ Denosumab can be self-administered subcutaneously in $60 \mathrm{mg}$ doses twice a year. ${ }^{90}$ Care must be taken though, as the effect of a single dose diminishes after six months, resulting in a rapid acceleration in bone turnover that places patients at a high risk of rapid bone loss and potential fracture (rebound-associated vertebral fractures) if a subsequent dose is missed. ${ }^{54,91,92}$ As with the bisphosphonates, ONJ and AFFs occur rarely in patients taking denosumab.91,93

Apart from the relatively recent introduction of denosumab, other novel strategies currently under development are also mainly focused on antibody therapy. On the anabolic side, osteocytes produce anabolic inhibiting sclerostin. The recent development of a monoclonal antibody against sclerostin, viz. romosozumab, has shown remarkable anabolic activity in bone with large increases in bone density. ${ }^{62,94}$ It has been shown to reduce the risk of fractures within 12 months and increases bone-mineral density at the hip and spine by the dual effect of increasing bone formation and decreasing bone resorption. ${ }^{95}$ Also, odanacatib, a selective cathepsin K-inhibitor with documented anti-fracture efficacy, ${ }^{96}$ prevents bone resorption. ${ }^{94}$ With respect to the parathyroid hormone signaling pathway, abaloparatide selectively activates the parathyroid hormone receptor type-1 (PTHR1) signaling pathway. ${ }^{97}$ It presents with an improved bone formation-resorption ratio, ${ }^{94}$ improves bone-mineral density and has the potential to reduce vertebral and non-vertebral fractures in postmenopausal women with osteoporosis, regardless of age, prior fracture history, or current bone-mineral status. ${ }^{97}$ It has recently been approved by the FDA for postmenopausal women with osteoporosis who are at high risk for fractures.

\section{A role for sequential combination therapy in the treatment of osteoporosis}

Osteoporosis, being a chronic disease, requires drug therapy for many years. The severity and progressivity of osteoporosis in some patients or therapeutic failure on monotherapy with antiresorptive drugs in others may necessitate the combination of drugs. Drug combinations are usually constituted between anabolic and antiresorptive drugs, ${ }^{98}$ although two antiresorptive drugs can also be combined. ${ }^{99}$ In this regard, numerous small clinical trials and case reports have shown that the combination of two antiresorptives, as well as an antiresorptive and an anabolic agent, results in significant improvements in bone mineral density compared to monotherapies. ${ }^{99,100}$ However, concerns have been raised regarding the safety of combining drugs, especially with regard to the potential over-suppression of bone turnover. Whereas an anabolic agent, e.g. teriparatide is indicated for 18-24 months in patients who still have severe and progressive osteoporosis despite antiresorptive treatment, ${ }^{100}$ sequential antiresorptive therapy is usually recommended to maintain increased bone-mineral density and to support secondary mineralization of the new bone tissue. ${ }^{100}$ The most consistent effect of combining antiresorptive agents, e.g. bisphosphonates/denosumab plus teriparatide, was found in the hip. ${ }^{101}$ It is recommended that in bisphosphonate-treated patients suffering from a very low or declining hip bone-mineral density and hip fractures, teriparatide should be initiated, while a potent bisphosphonate, e.g. zoledronic acid, or denosumab, should be continued with to improve and maintain the current bone-mineral status. The principle of quickly maximizing the bone-mineral density with combination or sequential therapy may also be of value in treatment-naive patients with severe osteoporosis and hip and spine fractures. ${ }^{101}$ To date, some of the findings with regards to the combination of drugs in the treatment of primary osteoporosis are still controversial while the effects of combination therapy remain unclear. This gap in the current knowledge base will hopefully be solved within the next couple of years. ${ }^{102}$

\section{References}

1. Lorenzo JA, Canalis E, Lawrence GR. Metabolic Bone Disease. In: Melmed S, ed. Williams Textbook of Endocrinology. Philadelphia: Elsevier Saunders; 2011:1305-49.

2. Raisz L, Shoukri K. Pathogenesis of osteoporosis. Physiology and pharmacology of bone: Springer; 1993:299-331.

3. Delany A, Amling M, Priemel M, Howe C, Baron R, Canalis E. Osteopenia and decreased bone formation in osteonectin-deficient mice. J Clin Invest. 2000;105(7):915.

4. Ducy P, Zhang R, Geoffroy V, Ridall AL, Karsenty G. Osf2/Cbfa1: a transcriptional activator of osteoblast differentiation. Cell. 1997;89(5):747-54.

5. Aarden EM, Nijweide PJ, Burger EH. Function of osteocytes in bone. J Cell Biochem. 1994;55(3):287-299.

6. Burger $\mathrm{EH}$, Klein-Nulend J. Mechanotransduction in bone-role of the lacunocanalicular network. The FASEB Journal. 1999;13(9001):S101-S112.

7. Karsenty G. Minireview: transcriptional control of osteoblast differentiation Endocrinology. 2001;142(7):2731-3.

8. Nakashima K, Zhou $X$, Kunkel $G$, et al. The novel zinc finger-containing transcription factor osterix is required for osteoblast differentiation and bone formation. Cell. 2002;108(1):17-29.

9. Koga $T$, Inui $M$, Inoue $K$, et al. Costimulatory signals mediated by the ITAM motif cooperate with RANKL for bone homeostasis. Nature. 2004;428(6984):758-63.

10. Dobreva G, Chahrour M, Dautzenberg $M$, et al. SATB2 is a multifunctional determinant of craniofacial patterning and osteoblast differentiation. Cell. 2006;125(5):971-86.

11. Tondravi $M$, McKercher $S$, Anderson $K$, et al. Osteopetrosis in mice lacking haematopoietic transcription factor PU. 1. Nature. 1997;386(6620):81-4.

12. Suda T, Takahashi N, Martin TJ. Modulation of osteoclast differentiation. Endocr Rev. 1992;13(1):66-80.

13. Recker R, Lappe J, Davies KM, Heaney R. Bone remodeling increases substantially in the years after menopause and remains increased in older osteoporosis patients. J Bone Miner Res. 2004;19(10):1628-33.

14. Hirano T, Turner C, Forwood M, Johnston C, Burr D. Does suppression of bone turnover impair mechanical properties by allowing microdamage accumulation? Bone. 2000;27(1):13-20. 
15. Canalis E, Centrella M, Burch W, McCarthy TL. Insulin-like growth factor I mediates selective anabolic effects of parathyroid hormone in bone cultures. J Clin Invest. 1989;83(1):60.

16. Eriksen $E$, Kudsk $H$, Emmertsen $K$, et al. Bone remodeling during calcitonin excess: reconstruction of the remodeling sequence in medullary thyroid carcinoma. Bone. 1993;14(3):399-401.

17. Giustina A, Mazziotti G, Canalis E. Growth hormone, insulin-like growth factors, and the skeleton. Endocr Rev. 2008;29(5):535-59.

18. Hofbauer LC, Gori F, Riggs BL, et al. Stimulation of osteoprotegerin ligand and inhibition of osteoprotegerin production by glucocorticoids in human osteoblastic lineage cells: potential paracrine mechanisms of glucocorticoidinduced osteoporosis. Endocrinology. 1999;140(10):4382-9.

19. Delany AM, Durant D, Canalis E. Glucocorticoid suppression of IGF I transcription in osteoblasts. Mol Endocrinol. 2001;15(10):1781-9.

20. Pereira RC, Jorgetti V, Canalis E. Triiodothyronine induces collagenase-3 and gelatinase B expression in murine osteoblasts. Am J Physiol Endocrinol Metab. 1999;277(3):E496-E504.

21. Moyer-Mileur LJ, Slater H, Jordan KC, Murray MA. IGF-1 and IGF-Binding Proteins and Bone Mass, Geometry, and Strength: Relation to Metabolic Control in Adolescent Girls With Type 1 Diabetes. J Bone Min Res. 2008;23(12):1884-91.

22. Falahati-Nini A, Riggs BL, Atkinson EJ, O'Fallon WM, Eastell R, Khosla S. Relative contributions of testosterone and estrogen in regulating bone resorption and formation in normal elderly men. J Clin Invest. 2000;106(12):1553.

23. Kanis J, Johnell O, Odén A, Johansson $H, M c C l o s k e y ~ E . ~ F R A X^{\mathrm{TM}}$ and the assessment of fracture probability in men and women from the UK. Osteoporos Int. 2008;19(4):385-97.

24. Ross $P$, Kress B, Parson R, Wasnich R, Armour K, Mizrahi I. Serum bone alkaline phosphatase and calcaneus bone density predict fractures: a prospective study. Osteoporos Int. 2000;11(1):76-82.

25. Hough S, Amod, A, Ascott-Evans BR, Brown SL, Cassim B, Davey M, et al. South African Clinical Guideline for the Diagnosis and Management of Osteoporosis: 2017. Durbanville; 2017.

26. Consensus A. Consensus development conference: diagnosis, prophylaxis, and treatment of osteoporosis. Am J Med. 1993;94(6):646-50.

27. Raisz LG. Pathogenesis of osteoporosis: concepts, conflicts, and prospects. J Clin Invest. 2005;115(12):3318.

28. Ralston SH, Galwey N, Mackay I, et al. Loci for regulation of bone mineral density in men and women identified by genome wide linkage scan: the FAMOS study. Hum Mol Genet. 2005;14(7):943-51.

29. Kaunitz AM, Arias $R$, McClung M. Bone density recovery after depot medroxyprogesterone acetate injectable contraception use. Contraception. 2008;77(2):67-76.

30. Riggs $B L$, Melton LJ, Robb RA, et al. Population-based study of age and sex differences in bone volumetric density, size, geometry, and structure at different skeletal sites. J Bone Min Res. 2004;19(12):1945-54.

31. Compston J. Secondary causes of osteoporosis in men. Calcif Tissue Int. 2001;69(4):193.

32. McKiernan $F$, Jensen $R$, Faciszewski T. The dynamic mobility of vertebral compression fractures. J Bone Min Res. 2003;18(1):24-9.

33. Mäkinen TJ, Alm JJ, Laine H, Svedström E, Aro HT. The incidence of osteopenia and osteoporosis in women with hip osteoarthritis scheduled for cementless total joint replacement. Bone. 2007;40(4):1041-7.

34. Nguyen ND, Pongchaiyakul C, Center JR, Eisman JA, Nguyen TV. Identification of high-risk individuals for hip fracture: a 14-year prospective study. J Bone Min Res. 2005;20(11):1921-1928.

35. Kharwadkar N, Mayne B, Lawrence J, Khanduja V. Bisphosphonates and atypical subtrochanteric fractures of the femur. Bone Joint Res. 2017;6(3):144-53.

36. Brunton LL, Lazo JS, Buxton ILO. Goodman \& Gilman's the pharmacological basis of therapeutics Buch. Buch, New York [u.a.]: McGraw-Hill Medical; 2011.

37. Pacheco-Pantoja EL, Alvarez-Nemegyei J. Statins and osteoporosis: a latent promise. Reumatol Clín (English Edition). 2014;10(4):201-3.

38. Conte P, Guarneri V. Safety of intravenous and oral bisphosphonates and compliance with dosing regimens. Oncologist. 2004;9(Suppl 4):28-37.

39. Kennel KA, Drake MT. Adverse effects of bisphosphonates: implications for osteoporosis management. Paper presented at: Mayo Clinic Proceedings, 2009.

40. Ruggiero SL, Fantasia J, Carlson E. Bisphosphonate-related osteonecrosis of the jaw: background and guidelines for diagnosis, staging and management. Oral Surg Oral Med Oral Pathol Oral Radiol Endod. 2006;102(4):433-41.
41. Khan RN, Jan SM, Ashraf T. Dental management of patients receiving bisphosphonate therapy-A review.

42. Kühl S, Walter C, Acham S, Pfeffer R, Lambrecht JT. Bisphosphonate-related osteonecrosis of the jaws-a review. Oral Oncol. 2012;48(10):938-47.

43. Khan AA, Morrison A, Hanley DA, et al. Diagnosis and management of osteonecrosis of the jaw: a systematic review and international consensus. J Bone Min Res. 2015;30(1):3-23.

44. Fung P, Bedogni G, Bedogni A, et al. Time to onset of bisphosphonate-related osteonecrosis of the jaws: a multicentre retrospective cohort study. J Oral Dis. 2017;23(4):477-83.

45. Donnelly $E$, Saleh A, Unnanuntana A, Lane JM. Atypical femoral fractures: epidemiology, etiology, and patient management. Curr Opin Support Palliat Care. 2012;6(3):348.

46. Boskey AL. Bone composition: relationship to bone fragility and antiosteoporotic drug effects. Bonekey Rep. 2013;2.

47. Anagnostis P, Paschou SA, Mintziori G, et al. Drug holidays from bisphosphonates and denosumab in postmenopausal osteoporosis: EMAS position statement. Maturitas. 2017.

48. Cano A, Chedraui P, Goulis DG, et al. Calcium in the prevention of postmenopausal osteoporosis: EMAS clinical guide. Maturitas. 01 Jan 2018;107(Suppl C):7-12.

49. Lewis JR, Radavelli-Bagatini S, Rejnmark $L$, et al. The effects of calcium supplementation on verified coronary heart disease hospitalization and death in postmenopausal women: a collaborative meta-analysis of randomized controlled trials. J Bone Min Res. 2015;30(1):165-175.

50. Pines A, Langer R. The cardiovascular safety aspects of calcium supplementations: where does the truth lie? A personal perspective. Climacteric 2015;18(1):6-10.

51. Uusi-Rasi K, Kärkkäinen MU, Lamberg-Allardt CJ. Calcium intake in health maintenance-a systematic review. Food Nutr Res. 2013;57(1):21082.

52. Candelas G, Martinez-Lopez J, Rosario M, Carmona L, Loza E. Calcium supplementation and kidney stone risk in osteoporosis: a systematic literature review. Clin Exp Rheumatol. 2012;30(6):954-61.

53. Brunton LL, Lazo JS, Buxton ILO, et al. Goodman \& Gilman's the pharmacological basis of therapeutics. 11th ed. New York: McGraw-Hill; 2006.

54. Center J, Sheu A. Osteoporosis in postmenopausal women: key aspects of prevention and treatment; 2017.

55. Ishtiaq S, Fogelman I, Hampson G. Treatment of post-menopausal osteoporosis: beyond bisphosphonates. J Endocrinol Invest. 2015;38(1):13-29.

56. Manolagas SC. Birth and Death of Bone Cells: Basic Regulatory Mechanisms and Implications for the Pathogenesis and Treatment of Osteoporosis*. Endocr Rev. 2000;21(2):115-37.

57. Nelson ER, Wardell SE, McDonnell DP. The molecular mechanisms underlying the pharmacological actions of estrogens, SERMs and oxysterols: Implications for the treatment and prevention of osteoporosis. Bone. 01 Mar 2013;53(1):42-50.

58. Lindsay R, Bush TL, Grady D, Speroff L, Lobo RA. Therapeutic controversy: Estrogen replacement in menopause. J Clin Endocrinol Metab. 1996;81(11):3829-38.

59. Writing Group for the Women's Health Initiative I. Risks and benefits of estrogen plus progestin in healthy postmenopausal women: Principal results from the women\&\#39;s health initiative randomized controlled trial. JAMA. 2002;288(3):321-33.

60. Parente L, Uyehara C, Larsen W, Whitcomb B, Farley J. Long-term impact of the women's health initiative on HRT. Arch Gynecol Obstet. 2008;277(3):219-24.

61. Heiss $G$, Wallace $R$, Anderson $G L$, et al. Health risks and benefits 3 years after stopping randomized treatment with estrogen and progestin. JAMA. 2008;299(9):1036-45.

62. Tella SH, Gallagher JC. Prevention and treatment of postmenopausal osteoporosis. J Steroid Biochem Mol Biol. 01 July 2014;142(Suppl C):155-70.

63. Studd J. Variations on HRT; 2017.

64. Studd J. Estrogens as first-choice therapy for osteoporosis prevention and treatment in women under 60. Climacteric. 2009;12(3):206-9.

65. Shapiro S, De Villiers T, Pines A, et al. Risks and benefits of hormone therapy: has medical dogma now been overturned? Climacteric. 2014;17(3):215-22.

66. Ettinger B, Black DM, Mitlak BH, et al. Reduction of vertebral fracture risk in postmenopausal women with osteoporosis treated with raloxifene: Results from a 3-year randomized clinical trial. JAMA. 1999;282(7):637-45. 
67. Albertazzi P, Di Micco R, Zanardi E. Tibolone: a review. Maturitas. 16 Nov 1998;30(3):295-305.

68. Campisi R, Marengo FD. Cardiovascular Effects of Tibolone: A Selective Tissue Estrogenic Activity Regulator. Cardiovasc Drug Rev. 2007;25(2):132-45.

69. Reed MJ, Kloosterboer HJ. Tibolone: a selective tissue estrogenic activity regulator (STEAR). Maturitas. 30 August 2004;48(Suppl 1):4-6.

70. Pinto-Almazán R, Segura-Uribe JJ, Farfán-García ED, Guerra-Araiza C. Effects of Tibolone on the Central Nervous System: Clinical and Experimental Approaches. BioMed Res Int. 2017:1-9.

71. Cummings SR, Ettinger B, Delmas PD, et al. The Effects of Tibolone in Older Postmenopausal Women. N Engl J Med. 2008;359(7):697-708.

72. Ginsburg J, Prelevic G, Butler D, Okolo S. Clinical experience with tibolone (Livial $^{\circledR}$ ) over 8 years. Maturitas. 1995;21(1):71-6.

73. Dimitrakakis C, Keramopoulos D, Vourli G, Gaki G, Bredakis N, Keramopoulos A. Clinical effects of tibolone in postmenopausal women after 5 years of tamoxifen therapy for breast cancer. Climacteric. 2005;8(4):342-351.

74. Jackson G. Tibolone and the cardiovascular system. Eur Heart J Suppl. 2001;3(suppl_M):M17-M21.

75. Neer RM, Arnaud CD, Zanchetta JR, et al. Effect of Parathyroid Hormone (1-34) on Fractures and Bone Mineral Density in Postmenopausal Women with Osteoporosis. N Engl J Med. 10 May 2001;344(19):1434-41.

76. Orwoll ES, Scheele WH, Paul S, et al. The Effect of Teriparatide [Human Parathyroid Hormone (1-34)] Therapy on Bone Density in Men With Osteoporosis. J Bone Min Res. 2003;18(1):9-17.

77. Eriksen EF, Keaveny TM, Gallagher ER, Krege JH. Review: Literature review: The effects of teriparatide therapy at the hip in patients with osteoporosis. Bone. 1 Oct 2014;67:246-56.

78. Vahle JL, Long GG, Sandusky G, Westmore M, Ma YL, Sato M. Bone Neoplasms in F344 Rats Given Teriparatide [rhPTH(1-34)] Are Dependent on Duration of Treatment and Dose. J Toxicol Pathol. 01 June 2004;32(4):426-38.

79. Hodsman AB, Bauer DC, Dempster DW, et al. Parathyroid Hormone and Teriparatide for the Treatment of Osteoporosis: A Review of the Evidence and Suggested Guidelines for Its Use. Endocr Rev. 2005;26(5):688-703.

80. Leder BZ, Tsai JN, Jiang LA, Lee $\mathrm{H}$. Importance of prompt antiresorptive therapy in postmenopausal women discontinuing teriparatide or denosumab: The Denosumab and Teriparatide Follow-up study (DATA-Follow-up). Bone. 01 May 2017;98(Suppl C):54-8.

81. Shen Y, Gray DL, Martinez DS. Combined Pharmacologic Therapy in Postmenopausal Osteoporosis. Endocrinol Metab Clin North Am. 1 March 2017;46:193-206.

82. Pilmane M, Salma-Ancane K, Loca D, Locs J, Berzina-Cimdina L. Strontium and strontium ranelate: Historical review of some of their functions. Mater Sci Eng. 01 Sep 2017;78(Suppl C):1222-30.

83. Reginster JY, Seeman E, De Vernejoul MC, et al. Strontium Ranelate Reduces the Risk of Nonvertebral Fractures in Postmenopausal Women with Osteoporosis: Treatment of Peripheral Osteoporosis (TROPOS) Study. J Clin Endocrinol Metab. 2005;90(5):2816-22.

84. Meunier PJ, Roux C, Seeman E, et al. The Effects of Strontium Ranelate on the Risk of Vertebral Fracture in Women with Postmenopausal Osteoporosis. N Engl J Med. 2004;350(5):459-68.
85. Meunier PJ, Roux C, Ortolani S, et al. Effects of long-term strontium ranelate treatment on vertebral fracture risk in postmenopausal women with osteoporosis. Osteoporos Int. 01 Oct 2009;20(10):1663-73.

86. Bolland MJ, Grey A. A comparison of adverse event and fracture efficacy data for strontium ranelate in regulatory documents and the publication record. BMJ Open. 2014;4(10).

87. Reginster J-Y. Cardiac concerns associated with strontium ranelate. Expert Opin Drug Saf. 01 Sep 2014;13(9):1209-13.

88. Rizzoli R, Yasothan U, Kirkpatrick P. Denosumab. Nat Rev Drug Discov. 2010;9(8):591-592.

89. Cummings SR, Martin JS, McClung MR, et al. Denosumab for Prevention of Fractures in Postmenopausal Women with Osteoporosis. N Engl J Med. 20 Aug 2009;361(8):756-65.

90. Khosla S. Increasing Options for the Treatment of Osteoporosis. N Engl J Med. 20 Aug 2009;361(8):818-20.

91. Popp AW, Zysset PK, Lippuner K. Rebound-associated vertebral fractures after discontinuation of denosumab-from clinic and biomechanics. Osteoporos Int. 01 May 2016;27(5):1917-21.

92. Lamy O, Gonzalez-Rodriguez E, Stoll D, Hans D, Aubry-Rozier B. Severe reboundassociated vertebral fractures after denosumab discontinuation: 9 clinical cases report. J Clin Endocrinol Metab. 2016;102(2):354-8.

93. Vehmanen L, Suojanen J, Kontio R, Utriainen T, Blomqvist C. High frequency of osteonecrosis of the jaw among denosumab-treated prostate cancer patients. Acta Oncol. 02 Jan 2017;56(1):104-6.

94. Ferrari S. Future directions for new medical entities in osteoporosis. Best Pract Res Clin Endocrinol Metab. 01 Dec 2014;28(6):859-70.

95. Keaveny TM, Crittenden DB, Bolognese MA, et al. Greater gains in spine and hip strength for romosozumab compared to teriparatide in postmenopausal women with low bone mass. J Bone Min Res. 2017.

96. Harsløf T, Langdahl BL. New horizons in osteoporosis therapies. Curr Opin Pharmacol. 2016;28:38-42.

97. Cosman F, Hattersley G, Hu M-y, Williams GC, Fitzpatrick LA, Black DM. Effects of Abaloparatide-SC on Fractures and Bone Mineral Density in Subgroups of Postmenopausal Women With Osteoporosis and Varying Baseline Risk Factors. J Bone Min Res. 2017;32(1):17-23.

98. Dempster DW, Cosman F, Zhou H, Nieves JW, Bostrom M, Lindsay R. Effects of daily or cyclic teriparatide on bone formation in the iliac crest in women on no prior therapy and in women on alendronate. J Bone Min Res. 2016;31(8):1518-26

99. Um MJ, Cho EA, Jung H. Combination Therapy of Raloxifene and Alendronate for Treatment of Osteoporosis in Elderly Women. J Menopausal Med. 2017;23(1):56-62.

100.Palacios S, Mejia A. Antiresorptives and anabolic therapy in sequence or combination for postmenopausal osteoporosis. Taylor \& Francis; 2015.

101.Cosman F. Anabolic and antiresorptive therapy for osteoporosis: combination and sequential approaches. Curr Osteoporos Rep. 2014;12(4):385-95.

102.Lou S, Lv H, Chen Y, Zhang L, Tang P. Use of combination therapy in the treatment of primary osteoporosis: protocol for a network meta-analysis of randomised trials. BMJ Open. 2016;6(11):e012802.1 